\title{
Os projetos culturais e seu significado social
}

Liv Sovik

Resumo: Projetos culturais, de arte-educação ou socioeducativos, cujos públicos-alvo são a juventude pobre e negra, vêm ocupando cada vez mais espaço na mídia e no imaginário social. Objetos de entusiasmo na mídia, por pregarem a paz social, são criticados em círculos menores, considerados mais politizados. Apresenta-se primeiro, neste trabalho, uma análise que procura driblar essa polarização e, mesmo assim, descreve-los de maneira crítica. Por considerar essa análise ainda bastante superficial, voltamos-nos para o trabalho de Stuart Hall, autor de obras importantes sobre questões parecidas de juventude, imaginário e violência na cultura britânica, em busca de um método "mais científico" de investigação. São apresentadas então considerações sobre o método de Hall, conceituado a partir da leitura de um texto de Marx, e, por meio desse método são levantadas questões analíticas mais incisivas sobre o significado social dos projetos no atual momento.

Palavras-chave: projetos culturais; método de pesquisa; Stuart Hall.

Abstract: Cultural projects and their social significance - Cultural, art education or socio-educational projects, whose target audiences are poor black youth, have attracted increasing attention in Brazil's media and social imaginary. The media is enthusiastic about them because they preach social peace, but they are criticized in smaller, more politicized circles. This article presents an analytical description of these projects as a social phenomenon, seeking to avoid this polarization while maintaining a critical eye. Because this initial analysis is still fairly superficial, we turn to the work of Stuart Hall, who wrote on similar issues of youth, imaginaries and violence in British culture, in search of a "more scientific" method of investigation. The article then presents considerations about Stuart Hall's investigative method, which he adapts from Marx, and uses it to raise more incisive questions about the social significance of such projects at this time.

Keywords: art education projects; research method; Stuart Hall.

A fundação do Olodum, em 1979, marca o início da atual onda, na cena cultural urbana, de projetos culturais, de arte-educação ou socioeducativos, cuja missão é a de orientar setores jovens da população pobre do Brasil para a conquista da cidade, 
usando a cultura como ferramenta de educação para a transformação social. Seria difícil, talvez impossível, fazer um levantamento completo dessas organizações, embora o programa Cultura Viva, do Ministério da Cultura, com seus Pontos de Cultura, tenha tido contato com boa parte deles, e alguns pesquisadores já tenham avançado na análise do conjunto (ver, por exemplo, CALABRE et al, 2011; SOUZA, 2010).

Tais iniciativas são objetos de entusiasmo em debates públicos e alguns de seus líderes e fundadores são presença recorrente em programas de televisão, muitas vezes como autoridades sobre o que acontece nas favelas e comunidades similares. Pesquisadores e turistas estrangeiros vêm ao Brasil de diversos países para conhecê-los e são referências em aulas de ciências sociais nas universidades onde estão muito presentes. Não é raro descobrir que membros das classes abastadas os conheçam e apoiem; alguns, inclusive, fundaram projetos desse tipo.

Os projetos socioculturais são uma faceta da transformação do espaço público nacional nos últimos 20 anos. Apesar de diferenças consideráveis, são uma versão atual de um fenômeno que existiu, com pessoas comuns fazendo arte, no Teatro Experimental do Negro, nos anos 1940, e no CPC da UNE nos anos 1960. Os de hoje fazem parte de uma nova forma de ação política que não passa tanto pela mobilização social e pressão sobre governantes quanto pela abertura de avenidas para o reconhecimento da população pobre e negra, através da mídia e da superação, no ambiente da cultura, de hierarquias de classe e raça.

O Olodum tocou com Paul Simon no Central Park em 1991. Favelados do projeto de teatro carioca Nós do Morro apresentam Shakespeare em Londres e atores formados pelo projeto participaram do filme Cidade de Deus (2002) e de programas de televisão, como Cidade dos homens (2002-2005). Projetos de dança formam e exportam bailarinos para companhias de ponta e para o mercado internacional de arte e entretenimento.

MV Bill realizou e exibiu seu documentário, Falcão - os meninos do tráfico, na Rede Globo, em 2006, e integra hoje o elenco do programa de televisão Malhação. E novelas do horário nobre da TV Globo já foram protagonizadas por galãs negros formados no Bando de Teatro Olodum ou em outras iniciativas análogas. Tudo isso é fruto dos projetos e de sua bem-sucedida estratégia de visibilização da juventude pobre e majoritariamente negra, que, por sua vez, nasceram de uma conjuntura específica.

No Rio de Janeiro, os projetos surgem com força nos anos 1990, quando, com o processo de democratização governamental já instalado, a violência policial contra a população pobre entra em pauta. Essa violência, cujas estatísticas continuam chamando a atenção, tem como alvo principal a população de jovens negros de bairros pobres das grandes cidades. As chacinas da Candelária, em 23 de julho, e do Vigário Geral, dia 29 de agosto de 1993, levaram à fundação da Casa da Paz, do Viva Rio, e do AfroReggae, no mesmo ano. Se essas chacinas causaram uma reação construtiva, o que chama a atenção, ao se olhar para trás, é que fizeram parte de uma série maior de crimes. Ainda vivem 
na memória o desaparecimento por ação da polícia de 11 jovens da comunidade de Acari, no Rio de Janeiro, em 26 de julho de 1990 e, em 2 de outubro de 1992, a morte de cento e onze detentos no presídio do Carandiru, em São Paulo. Dentre as diversas reações à situação, destaca-se a criação de projetos culturais cujo público-alvo eram jovens pobres. Das cinzas da violência e da negação dos direitos, surge, então, a fênix da cultura.

O impacto dos projetos sobre a cena pública nacional vem, em parte, da reconhecida relação entre autorrepresentação e capacidade de ação. Os depoimentos entusiasmados são muitos, de participantes, quadros e lideranças desses projetos, e fazem sentido. A autoestima pode não ser suficiente, mas é condição necessária para "os de baixo" reconhecerem a própria capacidade e sentirem a liberdade de agir para mudar as relações sociais. A experimentação com novas narrativas sobre si é fundamental para abrir um espaço no mundo, para "entrar em cena", como disse certa vez o teatrólogo e diretor Paul Heritage, experiente protagonista da cena de projetos socioculturais no Brasil e no Reino Unido.

As novas versões de beleza humana encantam observadores e contribuem para a crescente presença pública de figuras antes tidas como periféricas. De alguma maneira, os sujeitos da arte-educação produziram novas figurações do jovem da periferia e da favela, assim como novos produtos culturais que interessavam à mídia.

Mas como entender o que está sendo dito, na cena da mídia e em espaços menores, por esses atores? Às vezes, seus discursos são de pouco impacto crítico. Por exemplo, o refrão do conhecido "Rap da felicidade" (MC Cidinho e Doca) deve ser música para os ouvidos de qualquer membro da classe A ou B ansioso por manter as coisas do jeito que estão.

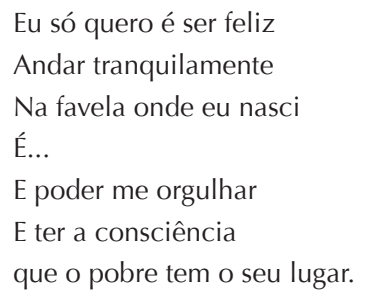

Esse lugar é do desemprego estrutural. Assim, os projetos são sujeitos a críticas por somente encenarem a inclusão social, pois o jovem formado em artes raramente consegue, na vida adulta, ganhar a vida com o que aprendeu: falta uma institucionalização e massificação das experiências educativas pelas quais passou. Por outro lado, a sustentabilidade dos projetos é precária: sua estrutura depende de doações, financiamentos de curto prazo do Estado ou de grandes corporações e seus programas de responsabilidade e marketing sociais. Para se manter, muitas vezes, dependem de uma ou outra pessoa que "sabe fazer" e cuja liderança é tanto imprescindível quanto potencialmente autoritária. Mas, sem essas pessoas, o projeto pode fechar e a situação dentro da comunidade piorar, pois uma esperança que morre é fator de despolitização. 
Os projetos culturais nos fascinam porque contêm elementos de toda a gama de relações de poder no Brasil urbano de hoje. Uma forma de entender seu significado seria chamar atenção para o fato de que seu eixo é a desigualdade estruturante da sociedade brasileira. Essa desigualdade é representada de múltiplas formas, desde a alardeada inclusão em seus quadros de ex-traficantes pelo AfroReggae, o florescimento da percussão afrobaiana do Olodum, como herança nacional, até o trabalho de jovens cineastas do projeto Nós do Morro no filme.

São exemplos variados, mas todos permitem, quando apresentados na grande mídia, que as classes abastadas observem e conversem sobre desigualdades abismais. Justo em uma época em que a empregada doméstica se torna mais cara e escassa e é reconhecida como sujeito de direitos, ela é substituída como meio de comunicação entre pessoas em níveis diferentes das hierarquias de classe e raça.

Mas a suspeição dos projetos não pode ser o único caminho analítico. Se a cena dos projetos culturais é madura, com modelos, formatos e fontes de financiamento, se já se estabeleceu uma tradição de desencadear a força criativa de jovens, se os projetos persistem através de décadas, eles têm um significado social importante. Não só tranquilizam as más consciências e nem todos folclorizam o jovem pobre e negro (como o faz o Galpão Aplauso, onde, em 2009, jovens espectacularizavam sua própria pobreza, fazendo piadas sobre a falta de dinheiro-para-a-passagem para participar do próprio projeto diante de uma plateia de gente trazida em ônibus lotado do Jockey Clube). Ao contrário, alguns formam pessoas atuantes vindas do mundo popular, trabalhadores das artes e de outros espaços. Também, evidenciam que podem trabalhar juntos, pessoas realizadas profissional e materialmente e jovens cujas carências e posição na estrutura social são obstáculos a essa mesma realização.

Esses atores falam da desigualdade social que os motiva a partir de lugares sociais diferentes, mas têm em comum o entusiasmo e a percepção de transformações, de tal maneira que suas vozes são às vezes quase indistinguíveis. Nesses casos de sucesso, apresentam respostas à pergunta: se temos em comum nossa humanidade, o que podemos fazer em comum?

\section{Problemas de método e o recurso a Hall}

O desafio dos projetos é de contornar as alternativas colocadas pelo senso comum: idealismo ou ceticismo. É preciso entendê-los como parte estrutural da sociedade, ou seja, precisa-se de um método menos retórico, mais conceitual, para entender seu sentido social. Aqui, opta-se por explorar o potencial das reflexões metodológicas de Stuart Hall.

Essa opção se deve a um segundo alvo deste trabalho: o de responder a algumas críticas a Hall e a seus estudos culturais. Dois exemplos: Figueiredo (2004) associa Stuart Hall a certo intelectual colonizado na metrópole, criticado por Frantz Fanon em obra 
de 1961, por negar sua conexão com seu povo de origem (p. 140); e ao intelectual globalizado na academia do Primeiro Mundo, que produz uma "palavra cosmopolita apartada da política local e, portanto, livre de um tipo de militância que a colocaria à prova" (p. 137).

O texto, intitulado "Exílios e diásporas", entende que o exilado sofre maior violência do que o diaspórico. A crítica parece deixar de lado a violência originária das diásporas e indicar que não existe política fora da Nação - ou dentro da Academia. O sarcasmo do título de um texto de Marcondes Filho, "Stuart Hall, cultural studies e a nostalgia da dominação hegemônica" (2008), é sintomático de um mal-estar mais geral com os estudos culturais, porque estes seriam teoricamente pobres e ligados a um esquerdismo ultrapassado.

O texto critica Hall sem conhecê-lo, ${ }^{1}$ mas a suspeita de insuficiência teórica que paira sobre Hall e os studos culturais merece uma resposta. O que os estudos culturais de Hall ainda podem render? Para esse exercício, adota-se o conceito de teoria do próprio Hall, quando afirma que um problema teórico é de natureza estratégica e política. ${ }^{2}$ Aqui se trata de entender o sentido dos projetos culturais como parte reconhecida da cena político-cultural brasileira. Sua força, nos últimos 20 anos, é um sinal de que? Como imaginar seu futuro?

O recurso a um autor muitas vezes se entende como ato de filiação. No caso de Hall, discute-se até que ponto é marxista. Para ele, entretanto, como tantos outros, a relação com teorias e teóricos é de interlocução, não adesão. Em "Estudos Culturais e seu legado teórico", palestra proferida em 1990, afirma: "Em nenhum momento os estudos culturais e o marxismo se encaixaram perfeitamente, em termos teóricos" (HALL, 2006, p. 191). O encaixe ficou por conta da teoria do capital e da classe social, do poder e da exploração, e da prática de produzir conhecimento crítico. O desencaixe resulta do reducionismo do economicismo do marxismo, do espaço pequeno destinado ao simbólico e do eurocentrismo que sustenta o modelo de transformação capitalista de Marx (ibid., p. 191-194).

Como entra o tema das identidades, pelo qual Hall é conhecido? Referindo-se ao relato biográfico de Gramsci no início de "A relevância de Gramsci para o estudo de raça e etnicidade" (HALL, 2006, p. 276-316), Hall explicou a relação entre suas discussões de Marx e de identidades sociais:

1 Marcondes Filho diz que Hall deve ser entendido como afiliado à sociolinguística e alinhado com Chomsky e Bourdieu, embora Hall fale da "virada linguística" mas não se limite a ela, entendendo-a como necessária numa conjuntura em que a análise socioeconômica predominava. Marcondes Filho ainda afirma que "oficialmente, a história dos Estudos Culturais inicia-se em 1956", junto com a New Left britânica, e implica que ambos tenham surgido como reação ao socialismo "praticado pelos russos" na invasão soviética de Budapeste (MARCONDES FILHO, 2008, p. 27). Parece referir-se a um relato pessoal de Hall sobre as condições históricas que antecederam em quase uma década a fundação do Centre for Contemporary Cultural Studies, na Universidade de Birmingham - sobre sua experiência durante esse período e com a New Left, ver Hall (2006, p. 395-404); sobre sua relação com a "história oficial" dos Estudos Culturais (ibid., p. 187ff). O artigo ainda lê a ideia de dominância, de Hall, como dominação. Afirma que Hall abandonou Althusser a favor de Gramsci, sem lhe permitir a sutileza de sua discussão de um ou de outro. Critica seu texto do início dos anos 1970, "Codificar/decodificar", como se fosse expressão atual do que Hall pensa. Chama John Fiske de "colaborador de Hall", embora não o tenha sido. Afirma que Hall quer resgatar uma autenticidade proletária, mas isso não procede.

2 Em texto de 1983, postulou a "ideologia" como "problema geral - um problema teórico, por ser também um problema político e estratégico" (HALL, 2006, p. 248-249). 
não é só biografia, mas localização histórica, [...] somos todos "localizados". A política da localização (espaço) e de conjuntura (tempo) forma as coordenadas, não da "determinação" [determination] mas do caráter determinado [determinancy], das coisas. Esse é o sentido [the drift] de todos meus longos engajamentos com Marx - da determinação ao caráter determinado das condições de existência. ${ }^{3}$

Aqui temos o "engajamento" com Marx como caminho para entender a contingência - não a determinação - das coisas. A identidade interessa como ponto no mapa de uma dada sociedade e momento histórico. O engajamento e o interesse pelas identidades não significa que Hall coloque a pragmática acima da teoria. Hall et al escreveram, na introdução de Policing the Crisis, uma extensa análise da conjuntura de um pânico moral, nos anos 1970, na Inglaterra, "Se alguém nos disser: 'Sim, mas dadas as atuais condições, o que devemos fazer agora?', só podemos responder, 'Tome uma atitude diante das atuais condições'” (HALL et al, 1978, p. x). Assim, a identidade social - locus classicus dos Estudos Culturais - interessa a partir de uma elaboração teórica das forças em jogo na sociedade.

O engajamento de Hall com Marx é principalmente com o método analítico marxista. "Acredito no poder e necessidade das ideias" disse Hall em 2004, em um autorretrato intelectual. Elas são necessárias para

entender o suficiente para fazer algo para afetar a conjuntura, quebrar a série de aparências congeladas e opacas com as únicas ferramentas que tem: conceitos, ideias e pensamentos. [...] Marx em sua Introdução de 1857 [aos Grundrisse], que é um texto metodológico maravilhoso sobre o qual já escrevi, [...] descreve precisamente esse processo. Estou falando aqui do método de trabalho de Marx. Não estou falando de assinarmos embaixo de todas as teorias do marxismo ou não. (HALL, 2007, p. 277) ${ }^{4}$

Acertar as contas com Marx, Althusser e o método marxista é o objetivo de "Marx's Notes on Method" (HALL, 2003), artigo que foi discutido no Centre for Contemporary Cultural Studies como working paper, no início dos anos 1970, e fundamentou pesquisas de Hall e outros, como Resistance Through Rituals (HALL; JEFFERSON, 1975) além de Policing the Crisis (HALL et al, 1978).

Hall abraça a crítica althusseriana ao humanismo marxista que postulava a reapropriação prática, pelo homem, de uma essência, a superação da alienação, insistindo na inexistência de garantias intrínsecas, prévias - da liberdade, da razão ou da comunidade - para posições políticas ou teóricas. Mas discorda da leitura de Marx por Althusser: este interpretaria erradamente a afirmação marxista de que o pensamento ocorre somente na cabeça do pensador, significando um paralelismo entre o pensamento e a sociedade; seriam como duas linhas que nunca se encontrassem.

3 A citação é de correspondência por email de Hall com a autora, datada de 3 de setembro 2002.

4 Os trechos citados, de textos cujos títulos constam em inglês nas referências, foram traduzidos pela autora. 
Para Hall, a relação entre a produção de conhecimento e o social, em Marx, é de convergência "no terreno do que é dado: no caso, a sociedade burguesa como terreno ou objeto de ambas, teoria e prática" (HALL, 2006, p. 137). Marx teria produzido "um método crítico capaz de penetrar por trás das formas dos fenômenos da sociedade para os movimentos ocultos, as 'relações reais' da estrutura profunda que estão por trás delas"' (HALL, 2003, p. 137).

Essa estrutura profunda, para Hall, é feita do que ele designou como "placas tectônicas" - econômica, ideológica, política, social, cultural. Ela é composta pelas "condições dadas de existência, a estrutura das determinações em qualquer situação [que] pode também ser compreendida, de outra perspectiva, como simples resultado de práticas anteriores" (HALL, 2006, p. 158).

Hall está interessado em Marx, primeiramente, por sua identificação de uma conexão interna entre processos. Quando o objeto de estudo é a produção, distribuição, troca e consumo na sociedade burguesa, é impossível separar consumo de produção, pois a produção exige o consumo de insumos. Por sua vez, o consumo estimula nova produção. Para Marx, no entanto, as relações não são simétricas: a produção prevalece sobre as demais etapas, é o elemento mais decisivo e organizador do ciclo. "Só a música desperta no homem o senso da música" (Marx apud HALL, 2003, p. 123); no final das contas, a produção musical condiciona, mais do que as outras "etapas", os modos de distribuição, troca e consumo. Resulta dessas inter-relações uma recomendação metodológica de Hall: "Ao examinar qualquer fenômeno ou relação, devemos compreender sua estrutura interna [...] e também as outras estruturas às quais está acoplado e com as quais forma uma totalidade mais inclusiva". (Hall, 2003, p. 127)

Continua: "Ambas, as especificidades e as conexões [...] precisam ser demonstradas pela análise de relações concretas e conjunções" (HALL, 2003, p. 128). A segunda consideração metodológica, então, é sobre o uso marxista do conceito do concreto. Contrariando o pensamento convencional lógico-dedutivo em que a evidência embasa a abstração, o pensamento deve, para Marx, "'subir do abstrato para o concreto' e não vice versa" (HALL, 2003, p. 131). O exemplo de uma abstração dada por Marx, "a população", ao ser examinada, é composta de classes, que por sua vez, pressupõem intercâmbio, divisão de trabalho, trabalho assalariado, valor, dinheiro, preço, etc.

Resumindo, as considerações metodológicas de Hall em "Marx's Notes on Method" ressaltam uma afetação mútua precária, mas possível, entre o trabalho intelectual e as relações sociais ${ }^{5}$ e focalizam a "estrutura profunda" dos objetos em foco, suas determinações, especificidades e conexões, que se manifestam de maneira concreta e de maneira mutante em diversas conjunturas. A conjuntura em que mais escreveu, entre os anos 1970 e 1980, foi de processos de globalização, diáspora e transformação de nações e de nacionalidades, da descolonização e seu impacto sobre as identidades sociais - e da "centralidade da cultura" (ver HALL, 1997). É a conjuntura atual, disse ele, que é o objeto de sua pesquisa.

5 Hall discute um exemplo dessa convergência em Hall (2006, p. 200-201). 


\section{Questões relacionadas aos projetos culturais}

Uma maneira de pensar mais analiticamente sobre os projetos culturais seria, então, de observar as grandes categorias de economia, organização social, ideologia, cultura, para chegar a uma compreensão da atual conjuntura. Consideremos, então, as "placas tectônicas" sobre as quais os projetos culturais se apoiam para comentar as conexões internas e o acoplamento dos projetos a outras estruturas e levantar questões mais precisas do que aquela sobre se fazem bem ou são inócuos.

Em seus primórdios, projetos como Olodum recebiam fundos das agências de cooperação internacional. Hoje, com a ascensão do Brasil como país de renda média no cenário global, quase todas essas agências se retiraram. O financiamento de projetos culturais passa, então, por grandes empresas que precisam demonstrar sua responsabilidade social; ou, principalmente, durante o governo Lula, por fontes de financiamento oficiais, como o programa Cultura Viva do Ministério da Cultura, com seus Pontos de Cultura. ${ }^{6}$ A dimensão econômica traz outras implicações para a organização social e política.

Os projetos culturais surgem durante um período em que foram criadas organizações não governamentais, sob as diversas formas jurídicas, para realizar o trabalho de movimentos sociais e entidades de assistência social. O processo de "onguização", exigida pelas agências de cooperação para evitar o repasse de verbas a indivíduos, foi abrangente e hoje projetos só sobrevivem como ONGs, sob a liderança de pessoas oriundas das classes populares ou não.

Por outro lado, com a proliferação de ONGs e projetos culturais, o debate em torno do estatuto da organização e política populares tende a focar e, às vezes, reduzir-se à crítica da própria "onguização", agravada pelas denúncias de ONGs que representariam interesses políticos escusos ou até organizações criminosas. Um dos sentidos sociais dos projetos, pelo que têm de parentesco com movimentos sociais, é de ajudar a recolocar a questão das formas institucionais da organização política popular.

Os projetos jazem também na instância da "ideologia", palavra evitada por teóricos da cultura atuais, mas que Hall emprega, para designar a "fixação de significados através do estabelecimento, por seleção e combinação, de uma cadeia de equivalências", em torno da qual há conflitos (HALL, 2006, p. 154). Os projetos competem entre si por financiamentos das grandes estatais, especialmente a Petrobrás, onde existe uma burocracia própria; mas também de bancos, empresas de telefonia, fabricantes de produtos de beleza. Sob pressão econômica o empreendedorismo se tornou um mote e os projetos acabam refletindo os valores que orientam a ação e subjetividade empresariais - a gestão, a capacidade de liderança, o produto: o bom gestor ou negociante foi transformado em paradigma de bom cidadão e os projetos culturais fazem parte das engrenagens que fixam esse mote. ${ }^{7}$

6 Sobre o financiamento de projetos culturais através desse programa, ver Souza (2012).

7 O contexto histórico é, evidentemente, mais amplo. Dagnino $(2004 ; 2005)$ traça a história de como o discurso neoliberal e os movimentos de construção democrática entraram em conflito em torno da fixação do sentido de termos como cidadania, sociedade civil, participação e solidariedade. 
A cultura da mídia é um importante espaço em que a governabilidade é negociada e os projetos responderam à procura, pelos grandes meios de comunicação, de narrativas que reestabelecessem um vínculo social entre os "de cima" e os "de baixo", em meio à preocupação com a violência urbana. A visibilidade tem usos políticos, mas a presença dos projetos no imaginário social também fala de outra coisa: de uma certa "moda" das artes e do entretenimento como algo que aproxima simbolicamente setores diferentes. Quando esses projetos deixarão de ser necessários? Se os projetos parecem um dado natural da cena cultural, existem forças que diminuem (ou ampliam) essa importância? Em que momento e condições sairiam de moda? São perguntas relacionadas com forças externas aos projetos.

Os projetos se dedicam ao empowerment dos jovens, sua maior autonomia ou ascensão social, mas a visibilidade parece absorver, muitas vezes, o espaço dedicado à educação artística como caminho para a educação. Tendem a focalizar, ainda, a posição de classe, permanecendo na sombra as questões de raça e gênero, estruturantes do capitalismo. Isso, apesar dos beneficiários fazerem parte da "população em situação de risco", que é composta, como se sabe, de jovens negros, meninos mais do que meninas.

O conceito de empowerment inclui a capacidade autorreflexiva. Os jovens aprendem a entrar em cena, mas são capazes de comentar criticamente o espaço que hoje ocupam, inclusive suas dimensões de raça e gênero? Despertadas a capacidade crítica e a autoestima, elas impactam atividades para além das atividades específicas dos projetos? ${ }^{8} \mathrm{O}$ valor social dos projetos se medirá, em parte, pela presença de seus egressos no espaço público e, também, pelo impacto de suas novas modalidades de aprendizado sobre a educação escolar em crise.

Em Redes ou paredes? A escola em tempos de dispersão (2012), Sibilia discute os impasses da escola - disciplinar por natureza - e as epistemologias contemporâneas, ligadas ao empreendedorismo e às tecnologias instantâneas: as décadas de experiência de alguns projetos poderiam ser valorizadas, na busca de novos rumos para a educação formal.

A política do empoderamento gera uma nova sociabilidade. Criam-se espaços urbanos para a convivência de membros de classes sociais diferentes. Neles, deslancha-se a criatividade popular brasileira, na medida em que os jovens acionem seus repertórios culturais em novos contextos, de aprendizagem. Vale dizer que nem sempre a convivência gera integração; às vezes, a copresença produz um novo retrato da desigualdade, como no fascínio pela "conversão" de traficantes em quadros de ONG pelo AfroReggae, provocando horror e fascínio entre seus espectadores.

Uma dificuldade que esse e outros projetos enfrentam é a violência, como explicam Araújo et al (2006), em artigo que trata a violência como conceito analítico da organização social. Uma pergunta que merece resposta é o que se pode extrair desse novo terreno e tipo de interação entre pessoas que vivem em polos opostos da violência da sociedade brasileira, uns salvos, outros violentados por causa de sua identidade social? O que esses laboratórios

8 Estudos que lidam com problemas de desencaixe entre as epistemologias dominantes e as necessidades de saber dos públicos-alvo dos projetos foram feitos por Selles (2012); Silva (2011); Guazina (2011) e Matos (2012) 
humanos nos trazem, afinal, de potente? Parece que a busca de resultados ou produtos, como fruto do trabalho educativo com arte e cultura, acaba transformando os projetos em empreendimentos, mas ainda há elementos que abalam as estruturas arcaicas da subalternidade e contribuem para a transformação estrutural?

Pelo senso comum, os projetos culturais parecem fruto da vontade de indivíduos de dar um basta à violência urbana, de habitantes de bairros pobres de ter novas experiências, ou um jogo de marketing de grandes empresas, mas qual é o sentido social mais profundo dos projetos sociais? Para responder à pergunta, foram acionadas as considerações teórico-metodológicas de Stuart Hall, ampliando o foco da pergunta para incluir o contexto dos projetos. Hoje, os projetos são vinculados à economia da iniciativa privada e individual, ao empreendedorismo, como saída para a juventude pobre. Pode ser impossível alterar a relação econômica, encontrando novas fontes de financiamento, ou evitar a relação simbiótica entre a grande mídia e as lideranças dos projetos. Mas a incerteza em torno do que os jovens, de sexo masculino ou feminino, brancos ou negros, pensam sobre sua experiência de beneficiários e "garotos-propaganda" faz com que a dimensão política e epistemológica dos projetos emerja, nesta análise, como a faceta mais plástica dos projetos e, portanto, mais estratégica.

Em suma, no âmbito da capacidade crítica dos jovens atores e das relações sociais internas aos projetos, existe desconhecimento e talvez alguma imprevisibilidade. A visibilidade é importante, mas é possível que não seja tudo, na política (esta é a lição que as manifestações de rua, de 2013, deram).

Hall se mostra útil na contextualização dos projetos, para tirá-los do senso comum e renovar as questões que os rodeiam. Certamente, outros autores serão necessários para auscultar a forma de pensar e agir da juventude pobre do país e entender a contribuição à cultura e educação desses projetos socioculturais, nos quais uma pequena parte da juventude participa.

Liv Sovik é doutora em Ciências da Comunicação pela USP e professora da Escola de Comunicação da UFR); é organizadora da coletânea Da diáspora: identidades e mediações culturais e autora de Aqui ninguém é branco.

Isovik@gmail.com

\section{Referências}

ARAÚJO, S. et al. A violência como conceito na pesquisa musical: reflexões sobre uma experiência dialógica na Maré, Rio de Janeiro. TRANS Revista Transcultural de Música, n. 10, dez. 2006. Disponível em: <http://www.sibetrans.com/trans/p5/trans-10-2006>. Acesso em: 29 set. 2012.

CALABRE, L. et al. Avaliação de políticas públicas de cultura: o programa Cultura Viva.In: ENECULT ENCONTRO DE ESTUDOS MULTIDISCIPLINARES EM CULTURA. 7, Salvador. Anais... Salvador, 3-5 ago. 2011. CD-Rom. 
DAGNINO, E. Políticas culturais, democracia e projeto neoliberal. Revista Rio de Janeiro, n. 15, p. 45-65, jan-abr./ 2005.

Sociedade civil, participação e cidadania: de que estamos falando? In: MATO, D. (org.). Políticas de ciudadanía y sociedad civil en tiempos de globalização. Caracas: Faces/ Universidad Central de Venezuela, 2004, p. 95-110.

FIGUEIREDO, V. L. F. de. Exílios e diásporas. In: O papel do intelectual hoje. MARGATO, I.; GOMES, R. C. (orgs.). Belo Horizonte: Editora UFMG, 2004.

HALL, S. A centralidade da cultura. Rev. Educação e Realidade, v. 22, n. 2, jul-dez./ 1997. Disponível em: <http://www.educacaoonline.pro.br/index.php?option=com_content\&view=article\&id=117:acentralidade-da-cultura-notas-sobre-as-revolucoes-culturais-do-nosso-tempo\&catid=8: multicultura lismo\&ltemid=19>. Acesso em: 10 abr. 2012.

. Marx's Notes on Method: a "reading" of the "1857 Introduction". Revista Cultural Studies, v.17, n. 2, p.113-149, 2003.

Da diáspora: identidades e mediações culturais. Belo Horizonte/Brasília: Editora UFMG/ Representação da Unesco no Brasil, 2006.

. Epilogue: Through the Prism of an Intellectual Life. In: MEEKS, B. (org.). Culture, Politics, Race and Diaspora: The Thought of Stuart Hall. Kingston/Londres: Ian Randle Publishers/Lawrence \& Wishart, 2007.

. et al. Policing the Crisis: Mugging, the State and Law and Order. Basingstoke: Palgrave Macmillan, 1978.

; JEFFERSON, T. (orgs.). Resistance through Rituals: Youth subcultures in post-war Britain. Londres: Hutchinson, 1976.

MARCONDES FILHO, C. Stuart Hall, cultural studies e a nostalgia da dominação hegemônica. Revista Communicare, v. 8, n.1, p. 25-42, 2008.

MATOS, D. A. Diários, mapas e mediações: comunicação, cultura e resistência da juventude periférica. Tese (Doutorado em Comunicação Social) - Universidade Federal de Minas Gerais, 2012.

SELLES, J. M. Música, desigualdade e conflito - perspectivas a partir do ensino de música em projetos comunitários. 2012. Texto para qualificação (Mestrado em Música) - Universidade Federal do Rio de Janeiro, Rio de Janeiro, 2012.

SIBILIA, Paula. Redes ou paredes? A escola em tempos de dispersão. Rio de Janeiro: Contraponto, 2012.

SILVA, A. D. da. A Maré no ritmo das ONGs: Uma análise sobre o papel das oficinas musicais de Organizações Não-Governamentais no bairro Maré/Rio de Janeiro. 2011. Dissertação (Mestrado em Música) - Universidade Federal do Rio de Janeiro, Rio de Janeiro, 2011.

SOUZA, V. N. de. de. Novo desenvolvimentismo brasileiro e democratização da cultura: o caso do Programa Cultura Viva. 2010. Dissertação (Mestrado em Serviço Social) - Escola de Serviço Social, Universidade Federal do Rio de Janeiro, 2010. Disponível em: https://sites.google.com/site/ secretariappgss/banco-de-teses-e-dissertacoes-do-ppgss. Acesso em: 30 jul. 2012. 